\title{
Novel targets for immunotherapy in glomerulonephritis
}

\author{
Mary H Foster \\ Department of Medicine \\ and Research Service, Duke \\ University Medical Center \\ and Durham Veterans Affairs \\ Medical Center, Durham, North \\ Carolina, USA
}

\begin{abstract}
Glomerulonephritis is a common cause of chronic kidney disease and end stage renal failure. Current therapy relies on variably effective, nonspecific and toxic immunosuppression. Recent insights into underlying biology and disease pathogenesis in human glomerulonephritis combined with advances in the fields of inflammation and autoimmunity promise a cadre of novel targeted interventions. This review highlights the therapeutic potential of two antigens, alpha3 (IV)NC1 collagen and podocyte neutral endopeptidase, and two cell signaling and effector molecules, IgG Fc receptors and complement, judged to be particularly amenable to therapeutic manipulation in man. It is anticipated that continued dissection of pathogenesis in the diverse disorders that comprise the glomerulonephritides will provide the basis for individualized disease-specific therapy.
\end{abstract}

Keywords: glomerulonephritis, immunotherapy, Goodpasture syndrome, membranous nephropathy

\section{Introduction}

Glomerulonephritis encompasses a cluster of diseases that have been described as the most common single cause of end stage renal disease (ESRD) in the world (Timoshanko and Tipping, 2005). GN was listed as the cause of ESRD in over 70,000 US patients in 2004 (US Renal Data System 2007). Glomerulonephritis and hypertension together are also the most common causes of chronic kidney diseases (CKD) in developing countries, and GN trails only hypertension and diabetes as a leading cause of CKD in the US, Europe, and Japan. Notably, for every patient with clinical GN, an estimated 5-10 patients have undiagnosed subclinical disease (Couser 1999). It is thus striking that an estimated 26 million Americans, or 13\% of the US adult population, and over 50 million individuals worldwide have CKD (Dirks et al 2005; Coresh et al 2007). Chronic GN may underlie pathogenesis of CKD in a significant proportion of this population. CKD not only places patients at risk for the various complications of renal damage, including increased cardiovascular disease and mortality, but it is estimated that each year more than one million CKD patients develop ESRD. Survival with ESRD requires renal replacement therapy with dialysis or transplantation, costly medical interventions not available in many developing countries. Clearly, effective therapy for GN would have significant impact globally on human health and health care financing.

GN is particularly prevalent among renal allograft recipients (Briganti et al 2002; Couser 2005). Glomerular diseases, including diabetes and glomerulonephritis, account for over $70 \%$ of patients receiving renal allografts, and in some countries GN alone accounts for up to $50 \%$ of patients (Briganti et al 2002). In a recent review of the Australian registry, among 1505 pts with biopsy-proven GN receiving a primary renal transplant between 1988 and 1997, recurrent or de novo GN occurred in 6\%-20\% of patients. Recurrence was the third most frequent cause of allograft loss at 10 years, after 
chronic rejection and death with a functioning transplant. Among patients transplanted due to GN, 8.4\% lost their allograft to recurrent GN by 10 years (Briganti et al 2002). These patients may particularly benefit from novel targeted therapies, since disease onset can be readily identified and intervention initiated promptly, if not pre-emptively.

\section{Definition of glomerulonephritis}

The glomerulonephritides comprise a group of immunologic diseases that damage the renal glomerulus, the filtering unit of the kidney. This network of capillaries, fed and drained by the afferent and efferent arterioles, respectively, filters plasma across the fenestrated endothelium, glomerular basement membrane (GBM) and podocyte slit diaphragms to collect in Bowman's space. Filtrate is dramatically modified as it passes through a series of tubules before delivery to the renal pelvis for excretion. The approximately 2 million glomeruli in normal adult kidneys filter over 150 liters of plasma per day. With this constant exposure and high filtering capacity, it is perhaps not surprising that the glomerulus is susceptible to injury from immune cells and their soluble products.

GN is defined as inflammation and cell proliferation in the glomerulus, although injury typically extends to the renal tubules, interstitium and vasculature. Common clinical findings include hematuria, proteinuria, and/or decreased glomerular filtration rate, detected as elevation in creatinine, often accompanied by hypertension, edema, and disease-specific findings. Immunopathogenesis is generally attributed to autoimmunity (see below), exacerbated by a local renal immune and inflammatory response. Common entities categorized as GN are indicated in Table 1. These include both renal-limited diseases and nephritides that develop as part of a systemic disorder, as well as those that have both renal-limited and systemic forms, such as antiGBM nephritis and its systemic counterpart, Goodpasture syndrome. Table 1 also includes several additional glomerulopathies with presumed immunologic origins but that are considered noninflammatory because they lack prominent cellular proliferation and infiltrates on renal histopathologic examination. These entities are often treated with immunosuppression regimens similar to those used to treat GN and thus are included in this review.

Current therapies for GN comprise a modest list of broadly immunosuppressive agents (Table 2). Efficacy can be striking, as observed with the combination of steroids and cyclophosphamide, and more recently mycophenolate mofetil, for induction and maintenance therapy in lupus
Table I Common glomerulonephritides and glomerulopathies with immune origins

Renal-limited disease

IgA nephropathy

Membranoproliferative glomerulonephritis (MPGN)

Anti-glomerular basement membrane disease

Pauci-immune glomerulonephritis

Systemic disease

Postinfectious glomerulonephritis

Lupus nephritis

Henoch-Schonlein purpura (HSP)

Goodpasture syndrome

Wegener's granulomatosis

Microscopic polyangiitis

Cryoglobulinemia

Additional glomerulopathies with immune origins

Membranous Nephropathy

Subset of focal sclerosing glomerulosclerosis (FSGS)

Subset of minimal change disease

Light chain deposition disease

nephritis and the ANCA vasculitides. Newer drugs developed initially to abrogate alloimmunity in transplantation have also proven effective in subsets of GN patients refractory to or intolerant of older established drugs. Nonetheless, these interventions support broad, non-specific blockade of the immune and inflammatory networks, demonstrate variable and often unpredictable efficacy, and carry significant toxicities, including infection, cancer, osteoporosis, avascular necrosis, amenorrhea, sterility, and alopecia. Clearly, more specific safer interventions are urgently needed for this diverse group of diseases. It is therefore notable that a variety of promising new approaches to restore specific immune tolerance to autoantigens, using protein-, cellular-, or gene-based therapies, have entered the clinical arena for multiple autoimmune diseases (Wolfraim 2006). Therapy for GN has lagged in this area, in part because the target antigens in most human immune nephritides remain elusive, unlike their experimental counterparts, and in part because little is

Table 2 Current common nonspecific therapies for glomerulonephritis

Glucocorticoids

Cyclophosphamide

Azathioprine

Chlorambucil

Intravenous immunoglobulin (IVIG)

Plasma exchange

Protein A immunoadsorption

Mycophenolate mofetil

Cyclosporine

Tacrolimus

Rapamycin 
known about immune regulatory mechanisms controlling nephritogenic lymphocytes. Our goal in this review is to examine in detail two antigens, alpha3 (IV)NC1 collagen and neutral endopeptidase, and two signaling and effector molecules, Fc $\gamma \mathrm{R}$ and complement, that are judged to be particularly amenable for novel therapeutic intervention in GN in man. The reader is referred to other recent reviews (Javaid and Quigg 2005; Foster 2007) and Table 3 for a

Table 3 Potential immunotherapy in autoimmunity and glomerulonephritis (after Foster 2007)

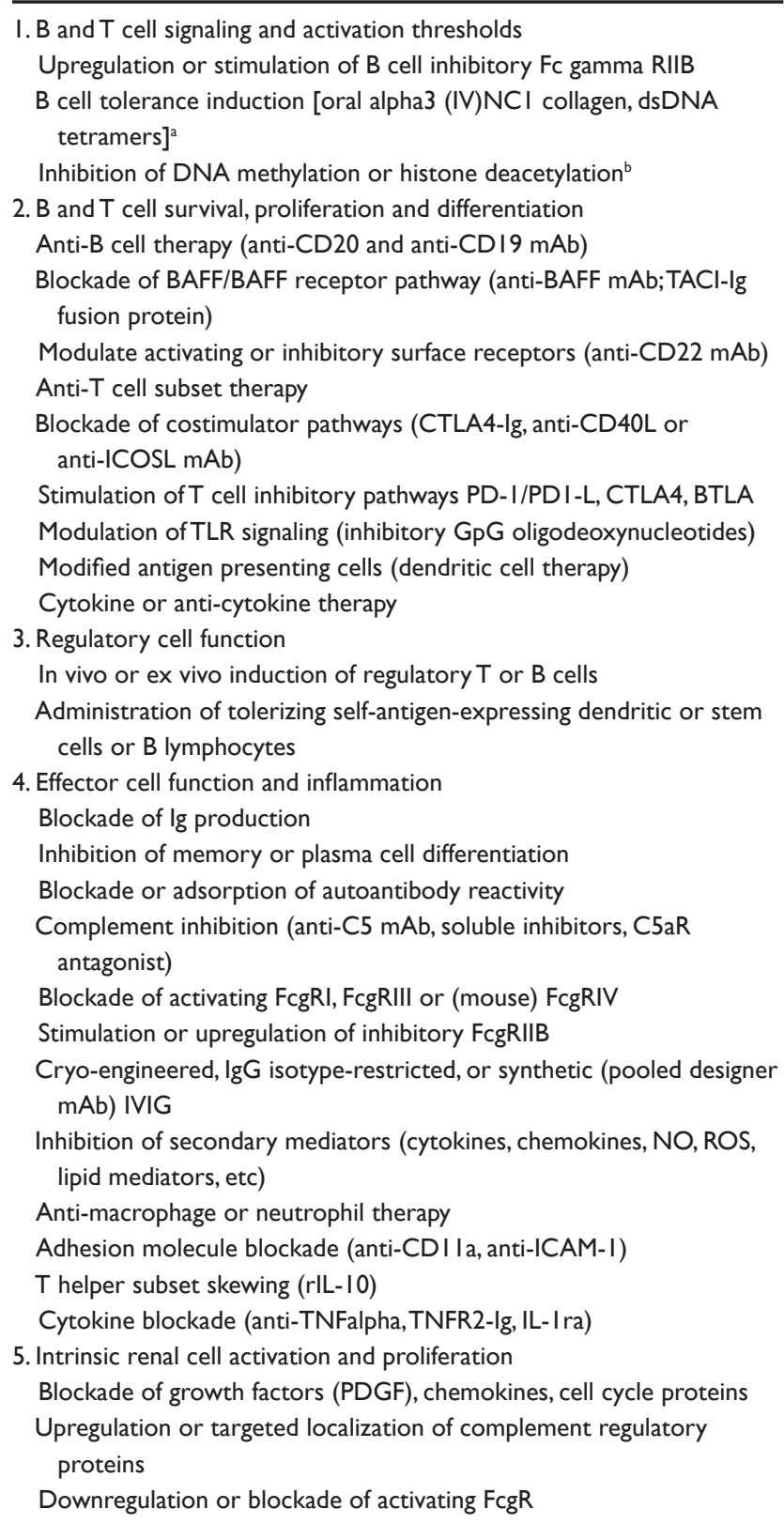

a Selected examples of interventions currently in preclinical or clinical trials are in parentheses.

bSome interventions modulate multiple checkpoints; for simplicity, only one category is shown.

Abbreviations: TLR, toll-like receptor; PD-I, programmed death-I; CTLA-4 (cytotoxic T lymphocyte antigen-4); BTLA, B and T lymphocyte attenuator. more comprehensive cataloguing of potential biologic interventions in GN.

\section{Glomerulonephritis: pathogenesis and potential therapeutic targets}

Considerable research in this field is focused on understanding the basic biology and pathogenesis of GN. Animal models have been particularly informative, both in highlighting the role of autoimmunity in the development of most GN and in providing in vivo tools with which to dissect the complex cell interactions that perpetuate disease and specific effector mechanisms that mediate tissue injury and inflammation. These models have revealed multiple targets for intervention, with disease specificity determined by the initiating antigen, the specific receptors on responding $\mathrm{B}$ and $\mathrm{T}$ lymphocytes, the glomerular antigen targeted locally, and the subset of downstream effectors recruited in a particular disease or individual (Figure 1).

Three of the most extensively studied animal models of nephritis involve antibody interactions with intrinsic glomerular protein. Autoimmune responses to glomerular basement membrane (GBM) alpha3 (IV) collagen and to glomerular epithelial cell (podocyte) membrane antigens can be induced by active immunization of animals with heterologous or autologous kidney extract. Resulting autoantibodies lead to nephritis marked by linear GBM Ig deposits (eg, autoimmune anti-GBM Ig-mediated disease) or disease dominated by granular subepithelial deposits (eg, active Heymann nephritis), respectively. Nonautoimmune nephritis with similar histopathologic characteristics can be induced by passive administration of preformed antigen-reactive antibodies. A third model, mesangioproliferative nephritis, is induced in rats by passive administration of antibodies that recognize a rat mesangial cell phosphatidylinositol-anchored glycoprotein, termed Thy- 1 antigen.

These models, as well as the spontaneous murine lupus models, provide considerable insight and are excellent tools with which to study downstream effector pathways. The specific mediators engaged vary by species, strain, and antigen preparation, and collectively effectively model the heterogeneous nephritis phenotypes observed in man (Table 1). Conversely, the models that depend on passive transfer of differentiated effectors or Ig provide minimal insight into the events that initiate and regulate renal-restricted autoimmunity. Also of unclear relevance to spontaneous human disease is the use of potent adjuvant in active immunization models. Elucidation of tolerance mechanisms that regulate nephritogenic autoreactivity will require novel autoreactive 


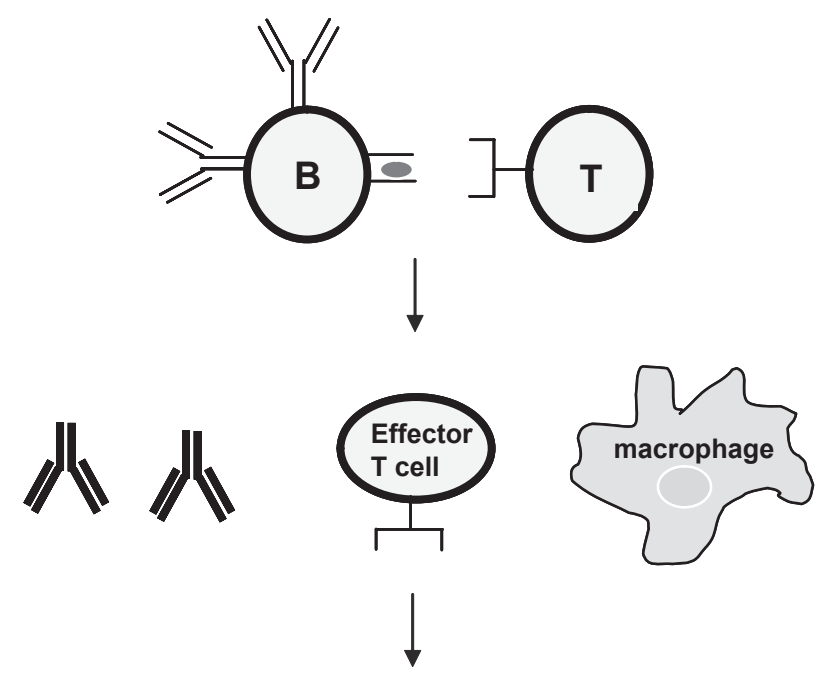

\section{Induction:}

Antigen

Loss of tolerance

Immune cell activation

\section{$\&$ interactions}

Downstream effectors:

Antibody, B cells, T cells

(Antigen-specific)

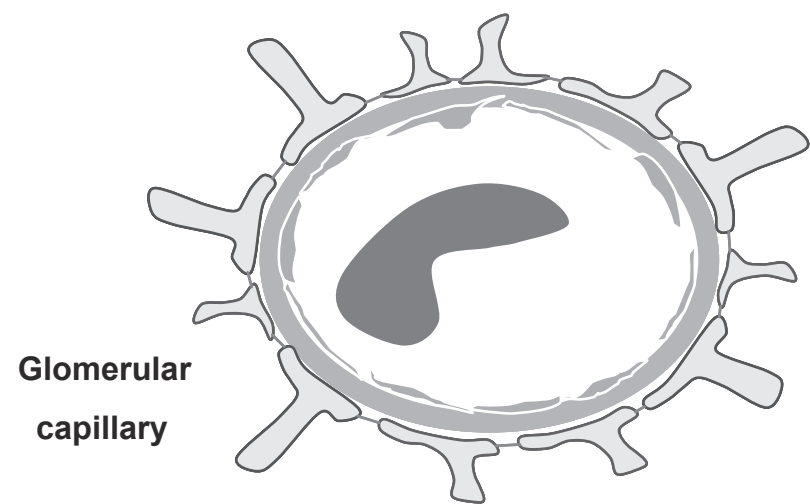

Complement

Macrophages, PMN

Intrinsic renal cells

Cytokines, chemokines

Oxidants, growth factors

Procoagulants

Figure I Pathogenesis of glomerulonephritis. Animal models suggest that autoimmunity underlies pathogenesis of most GN. Disease initiation requires loss of tolerance and activation of self-reactive lymphocytes. Activated B and T cells interact to promote autoantibody and cytokine production, immune complex formation, antibody deposition, macrophage and neutrophil recruitment, renal inflammation, and activation of renal endothelial, mesangial, epithelial and tubular cells. Glomerular and tubulointerstitial antigens may be specifically targeted by autoantibodies and self-reactive CD4 and CD8 TCR alpha/beta effector T cells, gamma/delta T cells and NKT cells. Numerous soluble and cellular mediators participate in subsequent tissue inflammation, injury and repair, and modulate local renal immune responses. The predominant cells and molecules engaged vary depending on the etiology and site of glomerular injury.

lymphocyte receptor transgenic models that target the relevant kidney antigens (Rudolph et al 2002; Zhang et al 2006).

\section{Antigen-based approaches}

Kidney antigen is an obvious target for achieving specificity in treating GN. Animal models engage a variety of cell-bound or soluble antigens either native to the glomerulus or that deposit on glomerular structures (Table 4). It is likely that similar antigens are involved in human GN, although to date only two classes of antigens have been confirmed in human disease: the noncollagenous (NC1) domains of the alpha 3 and 5 chains of type IV collagen in anti-GBM nephritis, and neutral endopeptidase in the rare but highly informative antenatal membranous nephropathy. These antigens will be considered in turn below, with regard to their therapeutic exploitation.

\section{Anti-GBM GN and Goodpasture syndrome}

The best characterized and until recently only confirmed kidney target in human GN is alpha3 (IV)NC1 collagen. A pathologic autoimmune response to this antigen leads to focal segmental proliferative and necrotizing $\mathrm{GN}$, frequently with crescent formation. This is associated with linear IgG deposition along the GBM, a pathologic hallmark of the disease. Co-involvement of the alveolar basement membrane with resultant pulmonary hemorrhage is termed Goodpasture syndrome (GPS). This restricted organ involvement is directly related to the restricted tissue expression of the target antigen.

Over the past two decades the molecular nature of the specific epitopes targeted by patient autoantibodies has been carefully dissected. The GBM collagen network is composed of heterotrimers of alpha3, alpha4 and alpha5 chains of type 
Table 4 Antigen targets in immune-mediated glomerular injury

\begin{tabular}{lc}
\hline Experimental models & Human \\
\hline Basement membrane antigens & Basement membrane antigens \\
Collagen, laminin & Alpha3 (IV)NCI \\
Heparan sulfate & (GPS, ARAS allograft) \\
Proteoglycan, chondroitin A & Alpha5(IV)NCI (XLAS allograft) \\
Intrinsic renal cell antigens & Intrinsic renal cell antigens \\
Endothelial cell & Neutral endopeptidase \\
Mesangial cell & (antenatal MN) \\
Podocyte (proteins, glycolipids) & \\
Soluble nuclear antigens & \\
DNA, histone, nucleosome & \\
Soluble immune elements & \\
Autologous Ig, Clq & \\
\hline Abbreviations: GPS, Goodpasture syndrome; ARAS, Autosomal recessive Alport \\
syndrome; XLAS, X-linked Alport syndrome; MN, membranous nephropathy.
\end{tabular}

IV collagen. Trimers self associate at their $\mathrm{NC} 1$ carboxyl termini, forming $\mathrm{NC} 1$ hexamers, and at their amino termini, forming a collagen IV network. The epitopes recognized by the high affinity IgG autoantibodies isolated from serum and kidney eluates of GPS patients have been localized to the $\mathrm{NC} 1$ domain of the alpha3 (IV) chain (Wieslander et al 1984; Saus et al 1988). These pathogenic epitopes are conformational and partially sequestered within the $\mathrm{NC} 1$ hexamer, minimally accessible for autoantibody binding unless hexamer dissociation into dimers or monomers exposes critical hydrophobic residues (David et al 2001; Borza et al 2002; Borza and Hudson 2003; Borza et al 2005). Environmental or genetic influences that facilitate hexamer dissociation may underlie disease susceptibility (Wilson 1997; Borza et al 2005; Kalluri et al 2000a). Binding to accessible hydrophilic residues by low affinity autoantibodies may also promote pathogenic epitope exposure by inducing conformational changes and stabilizing monomers (Borza et al 2000). Two immunodominant antibody epitopes recognized by the majority of GPS patient sera have been mapped using chimeric proteins bearing segments of the alpha3 (IV) chain superimposed on a nonimmunoreactive alpha1(IV)NC1 collagen framework (Hellmark et al 1999; Netzer et al 1999; Borza et al 2000). A restricted number of target epitopes is supported by demonstration of a shared idiotype, and thus shared structural determinant, among GPS serum autoantibodies (Meyers et al 1998).

Epitope and antibody characteristics suggest several targets for specific therapy in anti-GBM nephritis. Selective immunoadsorption using affinity columns coated with antigen can rapidly reduce circulating autoantibody titers in active disease. As proof of concept, affinity chromatography using either purified bovine or recombinant human alpha3
(IV)NC1 collagen completely and selectively depletes pathogenic autoantibodies from patient plasma (Boutaud et al 1996). Feasibility of this approach in the clinic is further suggested by the success of repetitive immunoadsorption in removing plasma anti-A or anti-B isotype agglutinins in man; when combined with standard anti-rejection immunosuppression, immunoadsorption permits long-term survival of ABO-incompatible kidney allografts (Donauer et al 2006). This approach has an advantage over the current practice of initiating plasmapheresis in acute GPS, in that it does not deplete protective anti-microbial IgG, a major concern in a patient receiving concurrent cyclophosphamide.

Administration of oral or nasal GBM, bovine alpha3 (IV)NC1 dimers or recombinant rat alpha3 (IV)NC1 collagen can prevent induction of anti-GBM nephritis in antigenimmunized rodents (Kalluri et al 1997; Reynolds and Pusey 2001; Reynolds et al 2005). The tolerance mechanisms remain unclear, although downregulation of Th1 T cell responses is implicated. This approach may have particular utility as pre-emptive therapy in a subset of patients in whom onset of antibody production can be anticipated, such as Alport patients undergoing renal transplantation (see below). The consequences of antigen administration in active disease are less clear and require further study to understand the potential for triggering allergic or pathogenic stimulatory signals.

Antigen-based interventions in lupus nephritis, which has been most extensively studied, are instructive. Proposed approaches include neutralization or depletion of antigenreactive autoantibodies, $\mathrm{B}$ cells, or $\mathrm{T}$ cells, using infusion of soluble antigen, peptide epitopes, antigen multimers or anti-idiotypic antibodies, either alone or linked to cytotoxins. It is reasoned that autoantigen epitopes recognized by pathogenic $\mathrm{B}$ and $\mathrm{T}$ cells can delay or reverse disease if administered in a dose and form that can anergize or delete pathogenic cells or induce inhibitory regulatory cells. In this regard, in lupus mice onset of nephritis can be delayed by biweekly subcutaneous administration of sub-nanomolar quantities of nucleosomal histone peptide (Kang et al 2005) or by intravenous injection of high doses of a synthetic consensus peptide based on unique T-cell stimulatory epitopes expressed within anti-DNA IgG variable regions (Hahn et al 2001). Immunization with peptide epitopes from anti-nucleosomal IgG variable regions has a similar effect (Stoll et al 2007). Tolerance depends in part on induction of antigen-specific regulatory $\mathrm{CD} 4+\mathrm{CD} 25+\mathrm{T}$ cells and CD8+ inhibitory $\mathrm{T}$ cells that secrete TGF-beta (La Cava et al 2004, 2005; Hahn et al 2005; Kang et al 2005). IL-10+ 
regulatory $\mathrm{T}$ cells induced by nasal histone peptide (Wu et al 2002) or high dose intravenous ribonucleoprotein peptide (Riemekasten et al 2004) are reported to provide protection in the (SWRxNZB)F1 and (NZBxNZW)F1 models of lupus nephritis, respectively. Murine lupus nephritis is also delayed by injection of a 21-mer laminin peptide recognized by a subset of pathogenic murine lupus autoantibodies (Amital et al 2005). The antigen peptide is located within the laminin alpha1 chain expressed in normal adult kidney mesangium and diseased GBM (Abrahamson et al 2003). In lupus patients, levels of anti-laminin autoantibodies correlate with disease activity and can be effectively removed by peptide-specific immunoadsorption (Amital et al 2007). In early human trials, lupus nephritic flares were prevented by administration of double stranded DNA tetramers that putatively adsorb and remove anti-DNA IgG and anti-DNA B cells (Alarcon-Segovia et al 2003); phase III clinical trials testing this reagent are ongoing (Furie 2006).

\section{Alport syndrome, alloantibodies and post-transplant anti-GBM GN}

Collagen epitopes also may be targeted therapeutically in patients with Alport syndrome who develop ESRD and undergo kidney transplantation. Alport patients develop a hereditary nephritis due to mutations in one of the genes encoding the alpha chains (alpha3, alpha4, or alpha5) of type IV collagen of the GBM (Hudson et al 2003). Ultrastructurally this is manifest as splitting, thickening and thinning of the involved basement membranes. Clinical consequences are related to the tissue distribution of these alpha(IV) chains and include progressive renal failure, sensorineural deafness and/or ocular abnormalities. Because Alport patients lack the corresponding collagen proteins and thus lack the Goodpasture epitopes in their native basement membranes (Olson et al 1980; McCoy et al 1982), those who undergo renal transplantation typically develop alloantibodies that bind GBM in the allograft but not the native kidneys. Of these, 3\%-5\% of patients will also develop anti-GBM GN, despite concurrent post-transplant immunosuppression. Although not all alloantibody target epitopes are known, alloantibody reactivity to $\mathrm{NC1}$ domains of all three alpha chains (alpha3, alpha4, or alpha5) is reported (Kalluri et al 2000b). Anti-alpha3 (IV)NC1 alloantibodies eluted from the failed renal allograft of one patient with autosomal recessive Alport syndrome and post-transplant anti-GBM GN recognized alloepitopes distinct from Goodpasture autoepitopes (Wang et al 2005). Thus, Alport patients in particular may benefit from targeted therapies, since disease onset can be readily identified and intervention initiated promptly, if not pre-emptively.

\section{Membranous nephropathy}

Membranous nephropathy (MN) is a common cause of CKD and accounts for approximately $20 \%$ of nephrotic syndrome in adult Caucasians (Ponticelli, 2007). By 10 years, $20 \%-40 \%$ of patients progress to ESRD. Given this considerable disease burden, novel effective disease-specific therapies are urgently needed. Important insight into disease pathogenesis was gleaned from study of the rat Heymann nephritis models (Couser and Nangaku 2006). Active HN is induced experimentally by immunization with kidney antigen preparations. Immunized rats develop marked proteinuria and glomerular pathology almost indistinguishable from human $\mathrm{MN}$ : thickened glomerular capillary basement membranes due to immune deposition exclusively in the subepithelial space. While it was initially believed that the granular deposits resulted from passive deposition of circulating immune complexes, key experiments subsequently revealed that antibody perfusion of isolated rat kidney led to immediate in situ formation of glomerular deposits (Couser et al 1978; Van Damme et al 1978). The target antigens were subsequently identified as megalin, a large membrane glycoprotein, multiligand endocytic receptor and member of the LDL-receptor-superfamily, and the receptor-associated protein, RAP, constitutively expressed on the rat glomerular podocyte foot processes (Kerjaschki and Farquhar 1982; Saito et al 1994; Farquhar et al 1995). Circulating pathogenic antibodies traverse the GBM, bind the megalin-RAP protein complex within the podocyte clathrin-coated pits, and shed as immune complexes that attach to the GBM. Additional autoantibodies in serum of rats with Heymann nephritis contribute to disease by binding distinct epitopes in the podocyte membrane including glycolipid and integrins to activate complement and induce proteinuria (Susani et al 1994).

Elucidation of pathogenesis in Heymann nephritis spurred a search for podocyte targets in human idiopathic MN. Megalin is not a candidate; although it is found in human renal proximal tubules, it has not been detected in human glomeruli or in immune deposits in patients with MN (Kerjaschki et al 1987). Alternative candidates include dipeptidyl-peptidase IV and neutral endopeptidase (NEP), both of which are expressed on human podocytes and implicated in glomerular immune deposition in experimental models (Ronco et al 1989; Ronco et al 1994), as well as unknown podocyte targets. NEP, an approximately $90 \mathrm{Kd}$ membrane-bound ectoenzyme, was recently identified as target antigen in a rare form 
of antenatal membranous nephropathy (Debiec et al 2002). Affected infants have subepithelial immune deposits and proteinuria at birth. Their mothers are phenotypically normal but genetically deficient in NEP due to truncating mutations in the Membrane MetalloEndopeptidase (MME) gene (Debiec et al 2004). During pregnancy, the fetus expresses normal NEP protein, the gene for which is inherited from the father. NEP-deficient mothers become alloimmunized to NEP in the placental syncytiotrophoblast and fetal tissues. Maternal anti-NEP IgG are transported across the placenta to the fetal circulation during the third trimester, cross the fetal GBM to bind NEP-expressing podocytes in developing glomeruli, and form immune complexes similar to those observed in experimental $\mathrm{HN}$.

\section{Therapeutic and diagnostic implications of NEP-induced MN}

Two immunodominant linear peptide NEP epitopes recognized by serum of alloimmunized mothers have been identified to date (Debiec and Ronco 2007). These epitopes may provide a basis for antigen-based therapies to prevent kidney injury in fetuses at risk. It is proposed that mothers of affected infants be monitored for circulating anti-NEP antibodies during subsequent pregnancies (Ronco and Debiec 2007). Rising titers can be managed either nonspecifically by plasma exchange, or in an antigen-specific manner using repetitive antigen adsorption. It is further proposed that undetected NEP-deficiency in transplant recipients with subsequent NEP alloimmunization may account for some cases of de novo MN in kidney allografts. Alloimmunization may similarly play a role in $\mathrm{MN}$ that develops after bone marrow or hematopoietic stem cell transplantation (Ronco and Debiec 2007). The degree to which maternal NEP-deficiency contributes to CKD in the general population is unknown, but likely to be low. However, observations from antenatal $\mathrm{MN}$ have rekindled hopes that nephritogenic podocyte antigens responsible for adult-onset $\mathrm{MN}$ will be identified, and ultimately provide novel targets for antigen-specific therapy.

\section{IgG Fc gamma receptors (FcyR) and complement as therapeutic targets in GN}

A large number of cellular and soluble mediators and modulators of immunity and inflammation and cell activation are implicated in immune activation, tissue destruction, remodeling and repair in GN (Fig. 1). Each of these is a potential target for therapeutic intervention (Table 3). The discussion below focuses on two modulators, IgG Fc gamma receptors (Fc $\gamma \mathrm{R})$ and complement, that are particularly amenable to therapeutic manipulation and for which a variety of therapeutic modulators are already in preclinical or early clinical trials.

Notably, whereas the discussion below focuses primarily on the role of Fc $\gamma \mathrm{R}$ and complement as effectors of renal inflammation, both molecules also modulate activation of B cells and follicular dendritic cells and thus have potent effects on humoral autoimmunity. Both cell types express inhibitory FcyRIIB that engages IgG as well as complement receptors type 1 (CR1, or CD35) and type 2 (CR2, CD21) that recognize activated products of $\mathrm{C} 3$ and $\mathrm{C} 4$ (reviewed in Nimmerjahn and Ravetch 2006, Roozendaal and Carroll, 2007). Thus, manipulation of these receptor-ligand interactions can alter initial lymphocyte tolerance and activation as well as modulate local renal effector mechanisms.

\section{Fc $\gamma R$}

IgG receptors link $\mathrm{IgG}$ or $\mathrm{IgG}$ immune complexes to effector cells by binding the $\mathrm{CH} 2$ domain of the Ig heavy chain constant, or Fc, region (Ravetch and Bolland 2001). Fc $\gamma \mathrm{R}$ are constitutively expressed on several cell types that contribute to pathogenesis in nephritis, including macrophages, dendritic cells, neutrophils, mast cells, endothelial cells and B cells, but not T lymphocytes (Nimmerjahn and Ravetch 2007). There is also evidence that Fc $\gamma R$ may be cytokine-inducible on parenchymal cells, including human mesangial cells (Radeke et al 1994). Many Fc $\gamma R$-bearing cells co-express two functional classes of Fc $\gamma \mathrm{R}$ : activating and inhibitory. Most activating receptors, Fc $\gamma \mathrm{RI}, \mathrm{Fc} \gamma \mathrm{RIII}$, Fc $\gamma R$ IIA and mouse Fc $\gamma R I V$, transmit signals via an adaptor protein, typically the common gamma chain coreceptor, that contains an ITAM (Immunoreceptor Tyrosine-based Activating Motif). Fc $\gamma$ RIIIB is unique in being glycosylphosphatidyl inositol-anchored with selective expression on neutrophils and eosinophils. The one inhibitory receptor, FcyRIIB, is a single chain receptor that transmits signals through an ITIM, or inhibitory motif. The balance of signaling from the two types of receptors sets the threshold for cell activation after stimulation by IgG or IgG-immune complexes. B cells express only inhibitory FcyRIIB, which negatively regulates activating signals from the B cell receptor.

Individual Fc $\gamma \mathrm{R}$ and allelic variants have restricted $\mathrm{IgG}$ isotype specificity and different affinities for the IgG isotypes (Nimmerjahn and Ravetch 2005; Nimmerjahn et al 2005). IgG1 binds the inhibitory Fc $\gamma$ RIIB and the activating Fc $\gamma$ RIII with low affinity, thus favoring inhibition under 
basal conditions, whereas IgG2a binds three activating Fc $\gamma \mathrm{R}$, Fc $\gamma R I, F c \gamma R I V$, and Fc $\gamma$ RIII, with varying affinities and binds inhibitory Fc $\gamma$ RIIB with low affinity, thus promoting cell activation. Notably, Fc $\gamma \mathrm{R}$ expression and $\mathrm{IgG}$ isotype are regulated by cytokines, and thus both can vary considerably during the course of disease and during therapy. Transforming growth factor-beta, IL-4 and IL-10 downregulate activating $\mathrm{Fc} \gamma \mathrm{R}$ and upregulate inhibitory Fc $\gamma \mathrm{RIIB}$ on most effector cells, and induce IgG1 and IgG3 isotypes. In contrast, interferon shifts the balance toward activating Fc $\gamma \mathrm{R}$ and production of IgG2a and IgG2b isotypes. Thus multiple factors determine the outcome of interactions between Fc $\gamma \mathrm{R}$ and $\mathrm{IgG} / \mathrm{immune}$ complexes.

\section{Fc $\gamma R$ in $G N$ and potential for therapeutic manipulation}

In human GN there is evidence that Fc $\gamma \mathrm{R}$ susceptibility alleles predispose to disease. Perhaps most compelling, Aitman and colleagues demonstrated not only that copy number of the FcyRIIIB gene (FCGR3B) varies between individuals, ranging from none to four copies per cell, but that low FCGR3B copy number and particularly absence of FCGR3B is associated with susceptibility to lupus nephritis (Aitman et al 2006; Fanciulli et al 2007). Increased risk for lupus nephritis is also described with polymorphisms in Fc $\gamma$ RIIB, Fc $\gamma$ RIIA and Fc $\gamma$ RIIIA in a subset of ethnic groups in some studies (Schwarting 2006).

Multiple observations in rodent experimental nephritis confirm that engagement of activating Fc $\gamma \mathrm{R}$ promotes nephritis whereas signaling via inhibitory Fc $\gamma$ RIIB ameliorates disease. In the nephrotoxic serum nephritis (NSN) model, susceptible animals are administered heterologous antiserum reactive with recipient GBM. Disease onset is accelerated by prior immunization with species-specific IgG. Because antigen (foreign Ig) is planted in the glomerulus in NSN, this model is used primarily to study downstream effector mechanisms that are recruited either by the deposited heterologous IgG or by the autologous anti-foreign-Ig immune response. In the Wistar Kyoto and related rat strains, susceptibility to NSN and macrophage hyperactivity is associated with a polymorphism in the activating Fc $\gamma \mathrm{R}$, Fc $\gamma \mathrm{R}$ IIIB (Aitman et al 2006). In murine NSN, disruption of the gene encoding the common Fc $\gamma \mathrm{R}$ gamma chain (Fc $\gamma \mathrm{R}-\mathrm{KO})$ renders activating Fc $\gamma R$ nonfunctional and markedly improves survival and prevents severe nephritis. Glomerular IgG and C3 deposits are unchanged in these mice, suggesting that protection involves interruption of events downstream of immune deposition (Park et al 1998; Wakayama et al 2000). Reciprocal bone marrow transplantation studies in murine accelerated NSN further show that protection depends on loss of Fc $\gamma \mathrm{R}$ expression on bone marrow-derived cells, presumably leukocytes (Tarzi et al 2002). Genetic deficiency of activating Fc $\gamma R$ also confers resistance to lupus nephritis in BWF1 mice, despite persistent serum autoantibodies and renal IgG and C3 deposits (Clynes et al 1998).

Mice administered monoclonal antibody to block activating receptor Fc $\gamma$ RIV were also protected from NSN (Kaneko et al 2006a). FcyRIV-expressing macrophages are recruited to glomerular lesions in this model, suggesting that disease is modulated at the site of tissue injury. Protection was not seen with control antibody infusion, by genetic deletion of Fc $\gamma$ RIII,

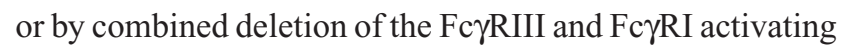
receptors. At the time of these studies a deletion model of Fc $\gamma$ RIV was not yet developed. Administration of high dose intravenous immunoglobulin, or IVIG, the pooled purified IgG fraction, or its Fc portion, also ameliorated nephritis in this model, concurrent with downregulated expression of FcyRIV on kidney-infiltrating leukocytes (Kaneko et al 2006a). IVIG also upregulated inhibitory Fc $\gamma$ RIIB; however, anti-Fc $\gamma$ RIV antibody therapy was effective in NSN in Fc $\gamma$ RIIB-deficient mice, confirming a key role for Fc $\gamma$ RIV in pathogenesis (Kaneko et al 2006a).

It is notable that the dominant activating Fc $\gamma \mathrm{R}$ engaged in NSN is model specific. C57BL/6 mice immunized with sheep IgG develop a dominant IgG2b mouse anti-sheep response (Kaneko et al 2006a). Mouse IgG2b binds both Fc $\gamma$ RIV and Fc $\gamma$ RIII, but with different affinities. Induction of NSN in mutant C57BL/6 mice rendered genetically deficient in these activating receptors revealed that Fc $\gamma \mathrm{RIV}$ is the major if not sole activating Fc $\gamma \mathrm{R}$ involved in pathogenesis in this model (Kaneko et al 2006a). In contrast, NSN induced in C57BL/6 mice using rabbit nephrotoxic serum is FcyRIII dependent (Fujii et al 2003). Thus, features of the inciting antigen help determine the nature of the subsequent immune response.

In contrast to the proinflammatory role of activating Fc $\gamma \mathrm{R}$, the inhibitory receptor Fc $\gamma$ RIIB is protective in several models of experimental nephritis. Genetic deletion of Fc $\gamma$ RIIB accelerates mortality in murine NSN (Kaneko et al 2006a), and leads to severe crescentic GN and massive pulmonary hemorrhage in mice immunized with collagen, an induced model of human spontaneous autoimmune GPS (Nakamura et al 2000). Deletion of FcyRIIB also leads to spontaneous autoimmunity and nephritis in a strain-dependent manner in susceptible normal backgrounds (Bolland and Ravetch 2000). Fc $\gamma R I I B-d e f i c i e n t ~ C 57 B L / 6$ mice develop proteinuria, immune complex deposition nephritis, activated lymphocytes, 
anti-chromatin autoantibodies, multiorgan inflammation, and early death. Conversely, deletion of FcyRIIB has no discernable phenotypic effect in the 129/B6 hybrid or BALB/c inbred backgrounds (Bolland and Ravetch 2000).

Protection afforded by Fc $\gamma$ RIIB appears to include effects at the level of both effector cells and B cell tolerance. Amelioration of NSN by high dose IVIG is accompanied by upregulated expression of FcyRIIB on kidney-infiltrating leukocytes (Kaneko et al 2006a), suggesting a direct effect on glomerular inflammation. In contrast, development of autoantibodies and proteinuria in Fc $\gamma$ RIIB-deficient C57BL/6 mice requires loss of FcyRIIB on B cells, not myeloid cells, as revealed by reciprocal bone marrow transfer experiments (Bolland and Ravetch 2000). This dual action is consistent with the roles of Fc $\gamma$ RIIB in setting activation thresholds for both B cells and myeloid cells.

Conversely, enhancing expression of inhibitory Fc $\gamma$ RIIB can restore tolerance and improve lupus nephritis. This approach was effective in three lupus strains, BXSB, NZM and B6.FcyRIIB-KO, subjected to isologous bone marrow transplantation (McGaha et al 2005). Donor bone marrow cells were transduced with vector carrying a DNA construct

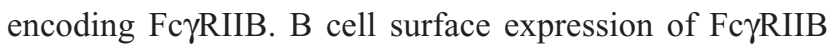
almost doubled in transplanted recipients. This was associated with significantly improved survival, reduced proteinuria, reduced autoantibody levels, reduced B cell activation, and improved nephritis and lung disease in each mouse strain compared to irradiated transplanted control mice that received mock-transduced bone marrow.

Fc $\gamma$ RIIB may play a key pathogenic role in systemic lupus erythematosus, and lupus nephritis in particular. Reduced Fc $\gamma$ RIIB expression on activated and germinal center B cells is reported in multiple strains of autoimmune mice, including NZB, NOD, BXSB, and MRL. Low FcyRIIB expression has been linked to polymorphisms in the gene promoter (Nimmerjahn and Ravetch 2006). In human lupus, reduced Fc $\gamma$ RIIB expression on activated B cells and inadequate upregulation of FcyRIIB on memory B cells are reported (Mackay et al 2006). These defects in man have been linked to polymorphisms in the Fc $\gamma$ RIIB transmembrane domain that impair the ability of FcyRIIB to enter lipid rafts (Floto et al 2005; Kono et al 2005,).

\section{Modulation of IgG glycosylation in glomerular inflammatory injury} $\mathrm{IgG}$ binding to Fc $\gamma \mathrm{R}$ requires Ig glycosylation (Kaneko et al 2006b). Over 30 different carbohydrate moieties covalently attach to the IgG Fc region via an N-linked glycan at asparagine 297. These glycans can have potent effects on IgG effector functions. The addition of the terminal sialic acid residue decreases IgG binding to selected Fc $\gamma \mathrm{R}$ by 5 - to 10-fold. In an experimental model in which an anti-platelet IgG1 mediates cytotoxicity in vivo, enrichment for IgG sialic acid markedly reduces antibody efficacy and minimizes platelet depletion (Kaneko et al 2006b).

IgG glycosylation is also important for the therapeutic efficacy of IVIG. In an experimental arthritis model, enrichment for sialic acid enhances IVIG efficacy, such that a 10-fold lower IVIG dose yields the same marked clinical improvement as does full dose nonenriched IVIG (Kaneko et al 2006b). In this arthritis model, the mechanism appears to involve sialic acid-enriched IVIG upregulation of inhibitory Fc $\gamma$ RIIB on macrophages. Conversely, enzymatic removal of all carbohydrate residues from IVIG eliminates most of its efficacy (Kaneko et al 2006b). These observations may explain the requirement for high doses of IVIG to achieve anti-inflammatory effects clinically; terminally sialylated IgG normally comprises only $5 \%$ of total serum $\mathrm{IgG}$, and thus of IVIG.

\section{Fc $\gamma R$ and lgG-based therapeutic strategies in $\mathrm{GN}$}

Fc $\gamma \mathrm{R}$ offer attractive targets for therapeutic modulation in nephritis. Potential approaches include blockade of the various activating Fc $\gamma \mathrm{R}$ using neutralizing monoclonal antibodies or small molecules, and upregulation or activation of inhibitory receptors, either on effector cells in target tissues or on pathogenic autoreactive B cells. IVIG is currently used therapeutically in nephritis primarily as salvage therapy in refractory disease (Toubi et al 2005). Recent advances in our understanding of mechanisms of action of IVIG provide a blueprint for enhancing its efficacy by glyco-engineering antibody preparations and selectively enriching for desired isotypes. Gene therapy combined with isologous bone marrow transplantation, an approach used to enhance FcyRIIB expression in rodents, is feasible in man. Ultimately, a tailored approach in which Fc $\gamma \mathrm{R}$-directed therapy takes into account the $\mathrm{IgG}$ isotype that dominates a given disease, the type of effector cells engaged, and the disease- or patient-specific Fc $\gamma \mathrm{R}$ profile has the potential to revolutionize therapy in GN.

\section{Complement and GN}

Glomerular complement deposition is common in immune complex mediated glomerular injury. Targeting complement for intervention, however, requires understanding of the 
complexity and diverse functions of the complement system (Gasque 2004). Over 30 proteins are engaged in the three major pathways of complement activation that converge on components $\mathrm{C} 3, \mathrm{C} 5$ and the terminal pathway that generates the C5b-9 membrane attack complex, or MAC: (1) The classical pathway initiated by immune complex recruitment of C1q, C4 and C2; (2) The alternative pathway in which activating surfaces engage $\mathrm{C} 3 \mathrm{~b}$ and factors $\mathrm{B}$ and $\mathrm{D}$; and, (3) The lectin pathway in which activation depends on microbial carbohydrate interaction with mannose-binding ligand. Activation generates: the anaphylatoxins C3a and C5a that engage specific cell membrane receptors, $\mathrm{C} 3 \mathrm{aR}$ and $\mathrm{C} 5 \mathrm{aR}$; $\mathrm{C} 3 \mathrm{~b}$ that associates with immune complexes; and, the C5b-9 membrane attack complex, or MAC, that inserts into cell membranes to induce sublytic or lytic injury. Complement activation is in turn regulated by a cadre of widely distributed soluble (factor $\mathrm{H}, \mathrm{C} 4 \mathrm{bp}$ ) and cell-bound (decay accelerating factor or DAF, membrane cofactor protein or MCP, CR1, CD59, and rodent CR1-related gene/protein y or Crry) complement inhibitors. Local renal production of complement components, constitutive and inducible renal cell expression of complement receptors and regulatory proteins, and accessibility of locally activated complement proteins to circulating or infiltrating receptor-bearing leukocytes influences the nephritis phenotype.

Complement proteins mediate a variety of key functions that promote immunity and inflammation to protect the host from microorganisms. These same functions occasionally induce autoimmunity and organ damage. Complement activation leads to adjacent cell activation, sublytic injury or death, myeloid cell chemotaxis and activation, and enhanced T-dependent humoral responses. The complement system can also dampen inflammation and immunity, by solubilizing, clearing and processing antigen, immune complexes and apoptotic debris, by regulating $B$ cell responses, and by helping to maintain B cell tolerance. Because of these divergent functions, the therapeutic potential of complement inhibitors in nephritis is complex.

This intricacy is reflected in the paradoxical roles of complement in lupus nephritis. A pathogenic role is supported by the presence of $\mathrm{C} 1 \mathrm{q}$ and $\mathrm{C} 3$ in inflamed glomeruli and correlation of low serum $\mathrm{C} 3$ and $\mathrm{C} 4$ levels with disease activity. Yet deficiency, not excess, of complement components $\mathrm{C} 1 \mathrm{q}$, $\mathrm{C} 2$ or $\mathrm{C} 4$ predisposes to SLE. This paradox is due in part to the primarily protective role of the early classical complement pathway. Genetic deficiency of C1q or C4 worsens nephritis and autoimmunity in murine lupus, and leads to spontaneous onset of autoimmune GN in susceptible normal strains
(Botto et al 1998; Prodeus et al 1998; Chen et al 2000; Einav et al 2002; Mitchell et al 2002; Paul et al 2002).

Conversely, the alternative pathway may contribute to renal damage. Genetic deficiency of factor B or factor D improves lupus nephritis in the MRL/lpr strain (Watanabe et al 2000; Elliott et al 2004), suggesting a predominantly pathogenic role for these components. The alternative pathway is also implicated in a subset of patients with membranoproliferative GN, or MPGN, types I and II. Genetic deficiency of the soluble complement regulatory protein, Factor $\mathrm{H}$, leads to continuous complement activation and $\mathrm{C} 3$ turnover in vivo. Pigs and mice with this deficiency develop MPGN that is amenable to therapy with anti-C5 monoclonal antibody (Hogasen et al 1995; Jansen et al 1998; Pickering et al 2002, 2006). A similar pathogenesis is suspected in the subset of patients with MPGN who have deficient factor $\mathrm{H}$ activity due either to mutations in Factor $\mathrm{H}$, to anti-factor $\mathrm{H}$ autoantibodies, or to $\mathrm{C} 3$ nephritic factor $(\mathrm{C} 3 \mathrm{NeF})$, an autoantibody that binds and stabilizes the alternative pathway C3bBb convertase (Meri et al 1992; Dragon-Durey et al 2004; Zipfel et al 2006).

Results in murine MRL/lpr lupus using blockade of C3, a common central component of the complement pathways, are inconsistent. Genetic deficiency of C3 worsens nephritis, suggesting a primarily protective role, similar to that proposed for C1q and C4 (Sekine et al 2001). In contrast, administration of the rodent $\mathrm{C} 3$ inhibitor Crry (CR1-related gene/protein y), either as a Crry-Ig fusion protein or in the form of transgenic soluble Crry, improves nephritis, consistent with a pathogenic role for C3 (Bao et al 2002, 2003).

The contribution of complement to pathogenicity in murine anti-GBM disease is equally complex. Deficiency of either $\mathrm{C} 3$ or $\mathrm{C} 4$ protects against nephritis in the heterologous phase of NSN (Sheerin et al 1997). Conversely, in the autologous phase of disease or in accelerated NSN, C3 deficient mice develop worse nephritis (Sheerin et al 2001). Deficiency of complement regulators CD59, a terminal pathway inhibitor, CD55 (decay accelerating factor, or DAF), a C3 inhibitor, double deficiency of CD59 and CD55, or double deficiency of CD55 and Crry exacerbates nephritis or proteinuria in murine NSN (Turnberg et al 2003; Lin et al 2004; Miwa et al 2007).

These diverse outcomes reflect the diverse roles for complement at multiple checkpoints during the immune response, including modulation of B cell activation, inflammation, and immune complex clearance. Additionally, some of these discrepancies may be the result of gaps in our understanding of complement biology. In this regard, 
Huber-Lang et al recently proposed a fourth pathway for complement activation that bypasses C3 (Huber-Lang et al 2006). This novel pathway depends on thrombin and tissue factor to independently generate $\mathrm{C} 5$ convertase to activate C5 and the terminal pathway. Lung injury induced by airway instillation of $\mathrm{IgG}$ immune complexes was equivalent in C3-sufficient and C3-deficient mice. Importantly, severe lung disease was ameliorated in both cases by administering antibody specific for C5a.

Renal injury resulting from the membrane attack complex, MAC or C5b-9, is best characterized in the noninflammatory passive Heymann nephritis model of membranous nephropathy induced in susceptible rat strains by injection of heterologous antiserum. Proteinuria is largely dependent on in situ complement activation triggered by podocyte-bound $\mathrm{IgG}$, leading to insertion of the MAC into the podocyte membrane and subsequent cell activation, sublytic injury and release of soluble mediators (Cybulsky et al 1986, 2005). By analogy, it is proposed that proteinuria in patients with $\mathrm{MN}$ is predominantly MAC-dependent, a view supported by demonstration of MAC in patient urine and renal biopsies (Schulze et al 1991). Interindividual and strain-dependent differences in mechanisms of proteinuria are likely, however, because proteinuria develops in active Heymann nephritis induced in the complement C6-deficient PVG/c rat strain (Leenaerts et al 1995).

\section{Complement therapeutics in GN}

Although as yet no complement-directed therapy has proven efficacy in nephritis, a variety of complement inhibitors are under development or in clinical trials in human autoimmune and inflammatory diseases (Morgan and Harris 2003; Turnberg and Cook 2005; Ricklin and Lambris, 2007). Inhibitors being tested include recombinant soluble forms of naturally occurring inhibitors, soluble complement receptor 1 (CR1), small molecule inhibitors of $\mathrm{C} 3$, blocking antibodies or single chain Ig Fv fragments against complement components such as $\mathrm{C} 5$, inhibitors of serine proteases, and anaphylatoxin analogues to antagonize $\mathrm{C} 3 \mathrm{aR}$ or $\mathrm{C} 5 \mathrm{aR}$. Realization that early components of the classical complement pathway have major protective roles in preventing autoimmunity has shifted focus in nephritis to inhibition of the alternative pathway or downstream complement components and local enhancement of complement inhibitors.

Anti-C5 antibody blocks generation of C5a fragment, $\mathrm{C} 5 \mathrm{~b}$ and the MAC. Anti-C5 Ig ameliorates lupus nephritis in the BWF1 strain and nephrotoxic serum nephritis in factor H-deficient mice (Wang et al 1996, Pickering et al 2006).
Prevention of spontaneous MPGN type II by disruption of the $\mathrm{C} 5$ gene in factor H-deficient mice suggests that anti-C5 antibody therapy may also be effective in the subset of MPGN patients with aberrant factor $\mathrm{H}$ activity (Pickering et al 2006; Smith et al 2007). The humanized monoclonal antibody to C5, eculizumab (Alexion), was approved by the FDA in early 2007 for use in patients with chronic hemolytic anemia due to paroxysmal nocturnal hemoglobinuria, an acquired genetic deficiency of complement inhibitors (Ricklin and Lambris, 2007). Eculizumab was well tolerated in patients with $\mathrm{MN}$ but a relatively short four month course failed to significantly reduce proteinuria (Appel et al 2002). The efficacy of antiC5 antibody therapy in other human glomerular diseases is yet to be established.

Systemically administered inhibitors that bind the C5aR are in preclinical studies. $\mathrm{C} 5 \mathrm{aR}$ is expressed on monocytes, neutrophils and cultured human mesangial cells (Braun and Davis, 1998) and increased in lupus nephritis kidneys (Abe et al 2001; Bao et al 2005). Pharmacological C5aR blockade using a small molecule antagonist prevents progressive lupus nephritis in MRL/lpr mice (Bao et al 2005).

Alternative strategies that target the site of complement activation and tissue injury in vivo are in development. Targeting permits local concentration of inhibitor while avoiding systemic effects that may compromise host defense or important physiological functions of C3 or C5. Efficacy was demonstrated in experimental proteinuria-induced renal tubulointerstitial injury using rat Crry or CD59 linked to a single chain Fv that targeted a rat proximal tubular epithelial cell antigen (He et al 2005). A fusion protein engineered to link complement receptor 2 (CR2), a binding partner for $\mathrm{C} 3$ activation fragments, to a soluble form of the membrane complement inhibitor DAF successfully targeted the inhibitor to inflamed kidney in mouse models of lupus nephritis (Song et al 2003). Ongoing investigation is dissecting the contributions of locally expressed complement components, receptors and regulatory proteins in experimental and human nephritis. It is anticipated that knowledge of the biology of complement in individual nephritides, throughout the course of disease and during concurrent immunosuppressive therapy, will ultimately permit appropriate therapeutic targeting.

\section{Summary and conclusion}

GN is a common cause of renal injury and CKD that continues to rely on non specific immunosuppression for therapeutic intervention. Recent insights into underlying biology and disease pathogenesis in human nephritis combined with advances in the fields of inflammation and autoimmunity 
bring the promise of new therapies. Notable breakthroughs include the discovery that alloimmunity to a glomerular antigen underlies antenatal membranous nephropathy, that podocytes are key regulators of glomerular filtration, that complement inhibitors are pivotal to pathogenesis in MPGN, and that IgG Fc receptors form a crucial link between antibody deposition and tissue injury. These discoveries provide the basis for novel therapies based on specific antigen or antibody responses or dominant effector cells or molecules engaged in individual nephritides. Future additional insights into cellular immunity, immune tolerance and regulatory networks, effector mechanisms, and genetic and environmental disease susceptibility will extend this armamentarium and provide the foundation for tailored individualized therapy.

\section{Abbreviations}

GN, glomerulonephritis; ESRD, end stage renal disease; CKD, chronic kidney disease; GBM, glomerular basement membrane; NSN, nephrotoxic serum nephritis.

\section{Acknowledgments}

This work was supported by National Institutes of Health Grant DK47424 and a Department of Veterans Affairs Merit Award.

\section{Disclosures}

Dr. Foster has served as a paid consultant for La Jolla Pharmaceutical Company.

\section{References}

Abe K, Miyazaki M, Koji T, et al. 2001. Enhanced expression of complement C5a receptor mRNA in human diseased kidney assessed by in situ hybridization. Kidney Int, 60:137-46.

Abrahamson DR, Prettyman AC, Robert B, et al. 2003. Laminin-1 reexpression in Alport mouse glomerular basement membranes. Kidney Int, 63:826-34.

Aitman TJ, Dong R, Vyse TJ, et al. 2006. Copy number polymorphism in Fcgr3 predisposes to glomerulonephritis in rats and humans. Nature, 439:851-5.

Alarcon-Segovia D, Tumlin JA, Furie RA, et al. 2003. LJP 394 for the prevention of renal flare in patients with systemic lupus erythematosus: results from a randomized, double-blind, placebo-controlled study. Arthritis Rheum, 48:442-54.

Amital H, Heilweil M, Ulmansky R, et al. 2005. Treatment with a lamininderived peptide suppresses lupus nephritis. J Immunol, 175:5516-23.

Amital H, Heilweil-Harel M, Ulmansky R, et al. 2007. Antibodies against the VRT101 laminin epitope correlate with human SLE disease activity and can be removed by extracorporeal immunoadsorption. Rheumatology (Oxford), 46:1433-7.

Appel G, Nachman P, Hogan S, et al. 2002. Eculizumab (C5 complement inhibitor) in the treatment of idiopathic membranous nephropathy (IMN): Preliminary baseline and pharmacokinetic (PK)/Pharmacodynamic (PD) data. J Am Soc Nephrol, 13:668A.

Bao L, Haas M, Boackle SA, et al. 2002. Transgenic expression of a soluble complement inhibitor protects against renal disease and promotes survival in MRL/lpr mice. J Immunol, 168:3601-7.
Bao L, Haas M, Kraus DM, et al. 2003. Administration of a soluble recombinant complement $\mathrm{C} 3$ inhibitor protects against renal disease in MRL/lpr mice. J Am Soc Nephrol, 14:670-9.

Bao L, Osawe I, Puri T, et al. 2005. C5a promotes development of experimental lupus nephritis which can be blocked with a specific receptor antagonist. Eur J Immunol, 35:2496-506.

Bolland S, Ravetch J. 2000. Spontaneous autoimmune disease in Fcgamma. RIIB-deficient mice results from strain-specific epistasis. Immunity, 13:277-85.

Borza D, Bondar O, Todd P, et al. 2002. Quaternary organization of the goodpasture autoantigen, the alpha 3(IV) collagen chain. Sequestration of two cryptic autoepitopes by intrapromoter interactions with the alpha 4 and alpha5 NC1 domains. J Biol Chem, 277:40075-83.

Borza DB, Bondar O, Colon S, et al. 2005. Goodpasture autoantibodies unmask cryptic epitopes by selectively dissociating autoantigen complexes lacking structural reinforcement: novel mechanisms for immune privilege and autoimmune pathogenesis. $J$ Biol Chem, 280:27147-54.

Borza DB, Hudson BG, 2003. Molecular characterization of the target antigens of anti-glomerular basement membrane antibody disease. Springer Semin Immunopathol, 24:345-61.

Borza DB, Netzer KO, Leinonen A, et al. 2000. The goodpasture autoantigen. Identification of multiple cryptic epitopes on the $\mathrm{NC1}$ domain of the alpha3 (IV) collagen chain. J Biol Chem, 275:6030-7.

Botto M, Dell'Agnola C, Bygrave AE, et al. 1998. Homozygous C1q deficiency causes glomerulonephritis associated with multiple apoptotic bodies. Nat Genet, 19:56-9.

Boutaud AA, Kalluri R, Kahsai TZ, et al. 1996. Goodpasture syndrome: selective removal of anti-alpha 3 (IV) collagen autoantibodies. A potential therapeutic alternative to plasmapheresis. Exp Nephrol, 4:205-12.

Braun M, Davis AE, 3rd 1998. Cultured human glomerular mesangial cells express the C5a receptor. Kidney Int, 54:1542-9.

Briganti EM, Russ GR, McNeil JJ, et al. 2002. Risk of renal allograft loss from recurrent glomerulonephritis. N Engl J Med, 347:103-9.

Chen Z, Koralov SB, Kelsoe G. 2000. Complement C4 inhibits systemic autoimmunity through a mechanism independent of complement receptors CR1 and CR2. J Exp Med, 192:1339-52.

Clynes R, Dumitru C, Ravetch JV. 1998. Uncoupling of immune complex formation and kidney damage in autoimmune glomerulonephritis. Science, 279:1052-4.

Coresh J, Selvin E, Stevens LA, et al. 2007. Prevalence of chronic kidney disease in the United States. JAMA, 298:2038-47.

Couser WG. 1999. Glomerulonephritis. Lancet, 353:1509-15.

Couser W. 2005. Recurrent glomerulonephritis in the renal allograft: an update of selected areas. Exp Clin Transplant, 3:283-8.

Couser W, Steinmuller D, Stilmant M, et al. 1978. Experimental glomerulonephritis in the isolated perfused rat kidney. $J$ Clin Invest, 62:1275-87.

Couser WG, Nangaku M. 2006. Cellular and molecular biology of membranous nephropathy. J Nephrol, 19:699-705.

Cybulsky AV, Quigg RJ, Salant DJ. 2005. Experimental membranous nephropathy redux. Am J Physiol Renal Physiol, 289:F660-71.

Cybulsky A, Rennke H, Feintzeig I, et al. 1986. Complement-induced glomerular epithelial cell injury. Role of the membrane attack complex in rat membranous nephropathy. J. Clin Invest, 77:1096-107.

David M, Borza D, Leinonen A, et al. 2001. Hydrophobic amino acid residues are critical for the immunodominant epitope of the Goodpasture autoantigen. A molecular basis for the cryptic nature of the epitope. J Biol Chem, 276:6370-7.

Debiec H, Guigonis V, Mougenot B, et al. 2002. Antenatal membranous glomerulonephritis due to anti-neutral endopeptidase antibodies. $N$ Engl J Med, 346:2053-60.

Debiec H, Nauta J, Coulet F, et al. 2004. Role of truncating mutations in MME gene in fetomaternal alloimmunisation and antenatal glomerulopathies. Lancet, 364:1252-9.

Debiec H, Ronco P. 2007. Fetomaternal alloimmunization with antenatal glomerulopathies. Ann N Y Acad Sci, 1110:559-66. 
Dirks JH, de Zeeuw D, Agarwal SK, et al. 2005. Prevention of chronic kidney and vascular disease: toward global health equity - the Bellagio 2004 Declaration. Kidney Int Suppl:S1-6.

Donauer J, Wilpert J, Geyer M, et al. 2006. ABO-incompatible kidney transplantation using antigen-specific immunoadsorption and rituximab: a single center experience. Xenotransplantation, 13:108-10.

Dragon-Durey MA, Fremeaux-Bacchi V, Loirat C, et al. 2004. Heterozygous and homozygous factor $\mathrm{H}$ deficiencies associated with hemolytic uremic syndrome or membranoproliferative glomerulonephritis: report and genetic analysis of 16 cases. J Am Soc Nephrol, 15:787-95.

Einav S, Pozdnyakova OO, Ma M, et al. 2002. Complement $\mathrm{C} 4$ is protective for lupus disease independent of C3. J Immunol, 168:1036-41.

Elliott MK, Jarmi T, Ruiz P, et al. 2004. Effects of complement factor D deficiency on the renal disease of MRL/lpr mice. Kidney Int, 65:129-38.

Fanciulli M, Norsworthy PJ, Petretto E, et al. 2007. FCGR3B copy number variation is associated with susceptibility to systemic, but not organspecific, autoimmunity. Nat Genet, 39:721-3.

Farquhar MG, Saito A, Kerjaschki D, et al. 1995. The Heymann nephritis antigenic complex: megalin (gp330) and RAP. J Am Soc Nephrol, 6:35-47.

Floto RA, Clatworthy MR, Heilbronn KR, et al. 2005. Loss of function of a lupus-associated FcgammaRIIb polymorphism through exclusion from lipid rafts. Nat Med, 11:1056-8.

Foster MH. 2007. T cells and B cells in lupus nephritis. Semin Nephrol, 27:47-58.

Fujii T, Hamano Y, Ueda S, et al. 2003. Predominant role of FcgammaRIII in the induction of accelerated nephrotoxic glomerulonephritis. Kidney Int, 64:1406-16.

Furie R. 2006. Abetimus sodium (riquent) for the prevention of nephritic flares in patients with systemic lupus erythematosus. Rheum Dis Clin North Am, 32:149-56.

Gasque P. 2004. Complement: a unique innate immune sensor for danger signals. Mol Immunol, 41:1089-98.

Hahn B, Singh R, La Cava A, et al. 2005. Tolerogenic treatment of lupus mice with consensus peptide induces Foxp3-expressing, apoptosisresistant, TGFbeta-secreting CD8+ T cell suppressors. J Immunol, 175:7728-37.

Hahn BH, Singh RR, Wong WK, et al. 2001. Treatment with a consensus peptide based on amino acid sequences in autoantibodies prevents $\mathrm{T}$ cell activation by autoantigens and delays disease onset in murine lupus. Arthritis Rheum, 44:432-41.

He C, Imai M, Song Het al. 2005. Complement inhibitors targeted to the proximal tubule prevent injury in experimental nephrotic syndrome and demonstrate a key role for C5b-9. J Immunol, 174:5750-7.

Hellmark T, Burkhardt H, Wieslander J. 1999. Goodpasture disease. Characterization of a single conformational epitope as the target of pathogenic autoantibodies. J Biol Chem, 274:25862-8.

Hogasen K, Jansen JH, Mollnes TE, et al. 1995. Hereditary porcine membranoproliferative glomerulonephritis type II is caused by factor $\mathrm{H}$ deficiency. J Clin Invest, 95:1054-61.

Huber-Lang M, Sarma JV, Zetoune FS, et al. 2006. Generation of C5a in the absence of C3: a new complement activation pathway. Nat Med, 12:682-7.

Hudson BG, Tryggvason K, Sundaramoorthy M, et al. 2003. Alport's syndrome, Goodpasture's syndrome, and type IV collagen. $N$ Engl J Med, 348:2543-56.

Jansen JH, Hogasen K, Harboe M, et al. 1998. In situ complement activation in porcine membranoproliferative glomerulonephritis type II. Kidney Int, 53:331-49.

Javaid B, Quigg RJ. 2005. Treatment of glomerulonephritis: will we ever have options other than steroids and cytotoxics? Kidney Int, 67:1692-703.

Kalluri R, Cantley L, Kerjaschki D, et al. 2000a. Reactive oxygen species expose cryptic epitopes associated with autoimmune Goodpasture syndrome. J Biol Chem, 275:20027-32.

Kalluri R, DanoffTM, Okada H, et al. 1997. Susceptibility to anti-glomerular basement membrane disease and Goodpasture Syndrome is linked to MHC class II genes and the emergence of T cell-mediated immunity in mice. J Clin Invest, 100:2263-75.
Kalluri R, Torre A, Shield CF 3rd, et al. 2000b. Identification of alpha3, alpha4, and alpha5 chains of type IV collagen as alloantigens for Alport posttransplant anti-glomerular basement membrane antibodies. Transplantation, 69:679-83.

Kaneko Y, Nimmerjahn F, Madaio MP, et al. 2006a. Pathology and protection in nephrotoxic nephritis is determined by selective engagement of specific Fc receptors. J Exp Med, 203:789-97.

Kaneko Y, Nimmerjahn F, Ravetch JV. 2006b. Anti-inflammatory activity of immunoglobulin G resulting from Fc sialylation. Science, 313:670-3.

Kang HK, Michaels MA, Berner BR, et al. 2005. Very low-dose tolerance with nucleosomal peptides controls lupus and induces potent regulatory T cell subsets. J Immunol, 174:3247-55.

Kerjaschki D, Farquhar M. 1982. The pathogenic antigen of Heymann nephritis is a membrane glycoprotein of the renal proximal tubule brush border. Proc Natl Acad Sci USA, 79:5557-61.

Kerjaschki D, Horvat R, Binder S, et al. 1987. Identification of a 400-kd protein in the brush borders of human kidney tubules that is similar to gp330, the nephritogenic antigen of rat Heymann nephritis. Am J Pathol, 129:183-91.

Kono H, Kyogoku C, Suzuki T, et al. 2005. FcgammaRIIB Ile232Thr transmembrane polymorphism associated with human systemic lupus erythematosus decreases affinity to lipid rafts and attenuates inhibitory effects on B cell receptor signaling. Hum Mol Genet, 14:2881-92.

La Cava A, Ebling FM, Hahn BH. 2004. Ig-reactive CD4+CD25+ T cells from tolerized New Zealand Black x New Zealand White.F1 mice suppress in vitro production of antibodies to DNA. J Immunol, 173:3542-8.

La Cava A., Fang CJ, Singh RP, et al. 2005. Manipulation of immune regulation in systemic lupus erythematosus. Autoimmun Rev, 4:515-9.

Leenaerts PL, Hall BM, van Damme BJ, et al. 1995. Active Heymann nephritis in complement component C6 deficient rats. Kidney Int, 47:1604-1614

Lin F, Salant DJ, Meyerson H, et al. 2004. Respective roles of decayaccelerating factor and CD59 in circumventing glomerular injury in acute nephrotoxic serum nephritis. J Immunol, 172:2636-42.

Mackay M, Stanevsky A, Wang T, et al. 2006. Selective dysregulation of the FcgammaIIB receptor on memory B cells in SLE. J Exp Med, 203:2157-64.

McCoy RC, Johnson HK, Stone WJ, et al. 1982. Absence of nephritogenic GBM antigen(s) in some patients with hereditary nephritis. Kidney Int, 21:642-52.

McGaha TL, Sorrentino B, Ravetch JV. 2005. Restoration of tolerance in lupus by targeted inhibitory receptor expression. Science, 307:590-3.

Meri S, Koistinen V, Miettinen A, et al. 1992. Activation of the alternative pathway of complement by monoclonal lambda light chains in membranoproliferative glomerulonephritis. J Exp Med, 175:939-50.

Meyers KE, Kinniry PA, Kalluri R, et al. 1998. Human Goodpasture antialpha3 (IV)NC1 autoantibodies share structural determinants. Kidney Int, 53:402-7.

Mitchell DA, Pickering MC, Warren J, et al. 2002. C1q deficiency and autoimmunity: the effects of genetic background on disease expression. J Immunol, 168:2538-43.

Miwa T, Zhou L, Tudoran R, et al. 2007. DAF/Crry double deficiency in mice exacerbates nephrotoxic serum-induced proteinuria despite markedly reduced systemic complement activity. Mol Immunol, 44:139-46.

Morgan BP, Harris CL. 2003. Complement therapeutics; history and current progress. Mol Immunol, 40:159-70.

Nakamura A, Yuasa T, Ujike A, et al. 2000. Fcgamma receptor IIB-deficient mice develop Goodpasture's syndrome upon immunization with type IV collagen: a novel murine model for autoimmune glomerular basement membrane disease. J Exp Med, 191:899-906.

Netzer KO, Leinonen A, Boutaud A, et al. 1999. The goodpasture autoantigen. Mapping the major conformational epitope(s) of alpha3 (IV) collagen to residues $17-31$ and $127-141$ of the NC1 domain. $J$ Biol Chem, 274:11267-74. 
Nimmerjahn F, Bruhns P, Horiuchi K, et al. 2005. FcgammaRIV: a novel FcR with distinct IgG subclass specificity. Immunity, 23:41-51.

Nimmerjahn F, Ravetch JV. 2005. Divergent immunoglobulin g subclass activity through selective Fc receptor binding. Science, 310:1510-2.

Nimmerjahn F, Ravetch J. 2006. Fcgamma receptors: old friends and new family members. Immunity, 24:19-28.

Nimmerjahn F, Ravetch JV. 2007. Fc-receptors as regulators of immunity. Adv Immunol, 96:179-204.

Olson DL, Anand SK, Landing BH, et al. 1980. Diagnosis of hereditary nephritis by failure of glomeruli to bind anti-glomerular basement membrane antibodies. J Pediatr, 96:697-9.

Park SY, Ueda S, Hamano Y, et al. 1998. Resistance of Fc receptor-deficient mice to fatal glomerulonephritis. J Clin Invest, 54:1229-38.

Paul E, Pozdnyakova OO, Mitchell E, et al. 2002. Anti-DNA autoreactivity in C4-deficient mice. Eur J Immunol, 32:2672-9.

Pickering MC, Cook HT, Warren J, et al. 2002. Uncontrolled C3 activation causes membranoproliferative glomerulonephritis in mice deficient in complement factor H. Nat Genet, 31:424-8.

Pickering MC, Warren J, Rose KL, et al. 2006. Prevention of C5 activation ameliorates spontaneous and experimental glomerulonephritis in factor H-deficient mice. Proc Natl Acad Sci USA, 103:9649-54.

Ponticelli C. 2007. Membranous nephropathy. J Nephrol, 20:268-87.

Prodeus AP, Goerg S, Shen LM, et al. 1998. A critical role for complement in maintenance of self-tolerance. Immunity, 9:721-31.

Radeke HH, Gessner JE, Uciechowski P, et al. 1994. Intrinsic human glomerular mesangial cells can express receptors for IgG complexes ( $\mathrm{hFc}$ gamma RIII-A) and the associated $\mathrm{Fc}$ epsilon RI gamma-chain. J Immunol, 153:1281-92.

Ravetch JV, Bolland S. 2001. IgG Fc receptors. Annu Rev Immunol, 19:275-90.

Reynolds J, Prodromidi EI, Juggapah JK, et al. 2005. Nasal administration of recombinant rat alpha3 (IV)NC1 prevents the development of experimental autoimmune glomerulonephritis in the WKY rat. $J$ Am Soc Nephrol, 16:1350-9.

Reynolds J, Pusey CD. 2001. Oral administration of glomerular basement membrane prevents the development of experimental autoimmune glomerulonephritis in the WKY rat. J Am Soc Nephrol, 12:61-70.

Ricklin D, Lambris JD. 2007. Complement-targeted therapeutics. Nat Biotechnol, 25:1265-75.

Riemekasten G, LangnickeL D, Enghard P, et al. 2004. Intravenous injection of a $\mathrm{D} 1$ protein of the Smith proteins postpones murine lupus and induces type 1 regulatory T cells. J Immunol, 173:5835-42.

Ronco P, Allegri L, Brianti E, et al. 1989. Antigenic targets in epimembranous glomerulonephritis. Experimental data and potential application in human pathology. Appl Pathol, 7:85-98.

Ronco PM, Ardaillou N, Verroust P, et al. 1994. Pathophysiology of the podocyte: a target and a major player in glomerulonephritis. Adv Nephrol Necker Hosp, 23:91-131.

Ronco P, Debiec H. 2007. Target antigens and nephritogenic antibodies in membranous nephropathy: of rats and men. Semin Immunopathol, 29:445-58.

Roozendaal R, Carroll M. C. 2007. Complement receptors CD21 and CD35 in humoral immunity. Immunol Rev, 219:157-66.

Rudolph EH, Congdon KL, Sackey FN, et al. 2002. Humoral autoimmunity to basement membrane antigens is regulated in C57BL/6 and $\mathrm{MRL} / \mathrm{MpJ}$ mice transgenic for anti-laminin Ig receptors. J Immunol, 168:5943-53.

Saito A, Pietromonaco S, Loo AK, et al. 1994. Complete cloning and sequencing of rat gp330/“megalin", a distinctive member of the low density lipoprotein receptor gene family. Proc Natl Acad Sci, USA. 91:9725-9.

Saus J, Wieslander J, Langeveld J, et al. 1988. Identification of the Goodpasture antigen as the alpha 3(IV) chain of collagen IV. J Biol Chem, 263:13374-80.

Schulze M, Donadio JV, Pruchno CJ, et al. 1991. Elevated urinary excretion of the C5b-9 complex in membranous nephropathy. Kidney Int, 40:533-8.
Schwarting A. 2006. Genetic predisposition - is lupus nephritis a question of copy numbers? Nephrol Dial Transplant, 21:2378-9.

Sekine H, Reilly CM, Molano ID, et al. 2001. Complement component C3 is not required for full expression of immune complex glomerulonephritis in MRL/lpr mice. J Immunol, 166:6444-51.

Sheerin NS, Springall T, Abe K, et al. 2001. Protection and injury: the differing roles of complement in the development of glomerular injury. Eur J Immunol, 31:1255-60.

Sheerin NS, Springall T, Carroll MC, et al. 1997. Protection against antiglomerular basement membrane GBM-mediated nephritis in C3- and C4-deficient mice. Clin Exp Immunol, 110:403-9.

Smith RJ, Alexander J, Barlow PN, et al. 2007. New approaches to the treatment of dense deposit disease. J Am Soc Nephrol, 18:2447-56.

Song H, He C, Knaak C, et al. 2003. Complement receptor 2-mediated targeting of complement inhibitors to sites of complement activation. J Clin Invest, 111:1875-85.

Stoll ML, Price KD, Silvin CJ, et al. 2007. Immunization with peptides derived from the idiotypic region of lupus-associated autoantibodies delays the development of lupus nephritis in the SWR x NZB.F1 murine model. J Autoimmun, 29:30-7.

Susani M, Schulze M, Exner M, et al. 1994. Antibodies to glycolipids activate complement and promote proteinuria in passive Heymann nephritis. Am J Pathol, 144:807-19.

Tarzi RM, Davies KA, Robson MG, et al. 2002. Nephrotoxic nephritis is mediated by Fcgamma receptors on circulating leukocytes and not intrinsic renal cells. Kidney Int, 62:2087-96.

Timoshanko JR, Tipping PG. 2005. Resident kidney cells and their involvement in glomerulonephritis. Curr Drug Targets Inflamm Allergy, 4:353-62.

Toubi E, Kessel A, Shoenfeld Y. 2005. High-dose intravenous immunoglobulins: an option in the treatment of systemic lupus erythematosus. Hum Immunol, 66:395-402.

Turnberg D, Botto M, Warren J, et al. 2003. CD59a deficiency exacerbates accelerated nephrotoxic nephritis in mice. $J$ Am Soc Nephrol, 14:2271-9.

Turnberg D, Cook HT. 2005. Complement and glomerulonephritis: new insights. Curr Opin Nephrol Hypertens, 14:223-8.

US Renal Data System. 2007. ESRD incidence and prevalence. In USRDS 2007 Annual Data Report: Atlas of Chronic Kidney Disease and EndStage Renal Disease in the United States, National Institutes of Health, National Institute of Diabetes and Digestive and Kidney Diseases, Bethesda, MD. pp 81-98.

van Damme B, Fleuren G, Bakker W, et al. 1978. Experimental glomerulonephritis in the rat induced by antibodies directed against tubular antigens. V. Fixed glomerular antigens in the pathogenesis of heterologous immune complex glomerulonephritis. Lab Invest, 38:502-10

Wakayama H, Hasegawa Y, Kawabe T, et al. 2000. Abolition of anti-glomerular basement membrane antibody-mediated glomerulonephritis in FcRgamma-deficient mice. Eur J Immunol, 30:1182-90.

Wang XP, Fogo AB, Colon S, et al. 2005. Distinct epitopes for antiglomerular basement membrane alport alloantibodies and goodpasture autoantibodies within the noncollagenous domain of alpha3 (IV) collagen: a janus-faced antigen. $J$ Am Soc Nephrol, 16:3563-71.

Wang Y, Hu Q, Madri JA, et al. 1996. Amelioration of lupus-like autoimmune disease in NZB/WF1 mice after treatment with a blocking monoclonal antibody specific for complement component C5. Proc Natl Acad Sci USA, 93:8563-8.

Watanabe H, Garnier G, Circolo A, et al. 2000. Modulation of renal disease in $\mathrm{MRL} / \mathrm{lpr}$ mice genetically deficient in the alternative complement pathway factor B. J Immunol, 15:786-94.

Wieslander J, Barr JF, Butkowski RJ, et al. 1984. Goodpasture antigen of the glomerular basement membrane: localization to noncollagenous regions of type IV collagen. Proc Natl Acad Sci USA, 81:3838-42.

Wilson CB. 1997. Immune Models of Glomerular Injury. In Neilson EG, Couser WG (Eds) Immunologic Renal Diseases. Philadelphia: Lippincott-Raven. 
Wolfraim LA. 2006. Treating autoimmune diseases through restoration of antigen-specific immune tolerance. Arch Immunol Ther Exp (Warsz), 54:1-13.

Wu HY, Ward FJ, Staines NA. 2002. Histone peptide-induced nasal tolerance: suppression of murine lupus. J Immunol, 169:1126-34.
Zhang Y, Su SC, Hecox DB, et al. 2006. Anti-Goodpasture autoantibodies escape regulation in a novel Ig transgenic model. J Am Soc Nephrol, 17:86 abst. Zipfel PF, Heinen S, Jozsi M, et al. 2006. Complement and diseases: defective alternative pathway control results in kidney and eye diseases. Mol Immunol, 43:97-106. 
